\title{
Improved district heating network operation by the integration of high-temperature heat pumps
}

\section{Kevin Sartor, Vincent Lemort \& Pierre Dewallef}

To cite this article: Kevin Sartor, Vincent Lemort \& Pierre Dewallef (2017): Improved district heating network operation by the integration of high-temperature heat pumps, International Journal of Sustainable Energy, DOI: 10.1080/14786451.2017.1383409

To link to this article: http://dx.doi.org/10.1080/14786451.2017.1383409

$$
\text { 曲 Published online: } 03 \text { Oct } 2017 .
$$

Submit your article to this journal $\pi$

Цll Article views: 9

Q View related articles $₫$

View Crossmark data $\nearrow$ 


\title{
Improved district heating network operation by the integration of high-temperature heat pumps
}

\author{
Kevin Sartor (1D), Vincent Lemort and Pierre Dewallef \\ Aerospace and Mechanical Engineering Department, University of Liège, Liège, Belgium
}

\begin{abstract}
Biomass combined heat and power (CHP) plants connected to district heating networks are a very good opportunity to increase the share of renewable sources into energy systems. Frequently, important consumers are connected to ensure a stable base heat demand throughout the year but they often have higher requirements in terms of temperature (i.e. steam), which involves a high level of temperature in the district heating network during the whole year and high levels of heat losses in the network. This contribution presents the possibility to decrease the level of temperature at which the district heating network operates and to use high-temperature heat pumps connected locally at the consumption point to produce steam when it is required. An investigation of the global design and integration through thermodynamic simulation models is realised for the University of Liège district heating network. This study is intended to determine the heat pump coefficient of performance and, therefore, to assess the balance between the savings in terms of heat losses and the additional heat pump electricity consumption.
\end{abstract}

\section{ARTICLE HISTORY}

Received 3 February 2017

Accepted 2 September 2017

\section{KEYWORDS}

District heating network; heat pump; application test case; heat losses

\section{Nomenclature}

CHP combined heat and power
COP coefficient of performance
DH district heating

\section{Introduction}

Biomass combined heat and power (CHP) plants are often seen as an efficient way to reduce greenhouse gases emissions due to their very low emissions level (Varun, Bhat, and Ravi 2009; Lund et al. 2010; Sartor, Quoilin, and Dewallef 2014). Moreover, biomass resources are more equally spread over the earth than fossil fuels, leading to a better energy independence for countries. But there exists plenty of biomass kind and a clean combustion of these fuels is generally more difficult to achieve than traditional fossil fuels. Therefore the investment costs of a biomass CHP plant are higher than the investment costs of a common CHP plant fed by natural gas (Danish Energy Agency 2012a) due to additional exhaust gas treatment costs.

Considering these additional costs, the efficiency of the CHP plant must be maintained as high as possible all over the year to be profitable. In practice, the baseline heat demand has to be considered to ensure a minimal number of hours per year during the CHP plant works at its nominal efficiency. Industrial processes are generally the best way to satisfy this criterion while they require a large and steady heat demand. Another developing idea is to use CHP plants to feed district heating networks 
(DHN). DHN are not new while they are used since the fourteenth century (Rezaie and Rosen 2012) and have been developed since 1950 (Dobos and Abonyi 2011) especially in Germany, Scandinavian countries and Eastern Europe countries.

In European Union, the rising price of fossil fuels and the awareness of limiting greenhouse gas emissions spotlights the use of DHN, leading to new installations for 15 years. Indeed the use of CHP plants fed by biomass is an opportunity to increase the renewable energies at an acceptable cost.

However, one must always keep in mind that even if a DH network enables the heat to be transported over long distances (typically several kilometres), which therefore guarantees a large amount of heat demand, the load profile throughout the year is far from being constant. Therefore, industrial consumers, tertiary buildings or hospitals are frequently connected to the DH network to ensure a steady base demand of heat throughout the year. However they often have requirements in terms of temperature levels such as steam, which involves maintaining a high level of temperature in the DH network during the whole year and thus increasing the level of heat loss in the network.

Previous works performed by the authors (see Sartor, Quoilin, and Dewallef 2014; Sartor et al. 2014) consider the simulation of a biomass CHP plant with the attached DH network to assess the cost of heat of such installations. This simulation model is able to assess the average conversion efficiency over a complete year of operation, thus providing reliable estimates for energy costs' predictions in function of the operating conditions, considering the incomplete combustion process from a generic biomass fuel of the type $\mathrm{C}_{\mathrm{m}} \mathrm{H}_{\mathrm{n}} \mathrm{O}_{\mathrm{s}} \mathrm{N}_{\mathrm{y}} \mathrm{S}_{\mathrm{x}}$. The example application proposed to enable the estimation of meaningful cost and environmental impacts related to the use of such installation.

The scope of this contribution is studying the improvements of a given DH network with some high-temperature requirement buildings by using high-temperature heat pumps connected locally at these consumption points to produce steam when required from lower temperature heat provided by the network. Therefore an economic and environmental balance is performed between the DH network heat loss reduction and the electric consumption of the heat pump. The electric consumption is assessed by a thermodynamic heat pump model which assesses the coefficient of performance of the heat pump. The present methodology is applied on an existing installation available on the University Campus in Liège (Belgium).

\section{Problem statement}

To maintain the profitability of a CHP plant connected to a DH network, important consumers such as industries, tertiary buildings or hospitals could be linked to DH network to ensure a minimum heat demand over the year, allowing a larger number of operating hours of the CHP plant. However, these consumers often have higher requirements in terms of temperature level as hot water over $100^{\circ}$ C or steam (Maxime Dupont ES 2009). To meet these requirements, the temperature of the DH network must be maintained high for the other consumers during the whole year. This situation involves higher heat losses due to the higher heat level transportation over large distances.

The proposed solution to limit these heat losses while guaranteeing the steam supply to consumers is to use high-temperature heat pumps to locally increase the temperature (namely at the substation(s) of the DH network where steam is required). Doing so, the steam needs are satisfied while reducing the heat losses related to the DH network. Even if these high-temperature heat pumps are not widely available nowadays, some studies can be found in the literature (see for example [Wang et al. 2010; Zhang, Wang, and Guo 2010; Peureux, Sapora, and Bobelin 2012; Wolf et al. 2012; Besbes 2015] for related research projects, [Chamoun et al. 2012] for a prototype test bench) and some dedicated high-temperature heat pumps are currently available for niche markets (Engines VH 2016). The scope of this study is to investigate the global design of a heat pump by performing a working fluid selection and to integrate the heat pump into the DHN systems by assessing the economic and environmental profitability of this solution. Here, the focus is put on the determination of the heat pump electricity consumption; the investments and operating costs will be from data available from the literature (Danish Energy Agency 2012b). To achieve this, a thermodynamic simulation model 
based on Quoilin et al. (2012) is realised to assess the coefficient of performance, which is defined as the ratio of the heating needs $(\dot{Q})$, to satisfy steam needs of customers, over electrical energy consumed, that is, in a first approximation the energy consumed by the compressor $(\dot{W})$ (neglecting the control system and any possible resistor to maintain at temperature the compressor when it is not used):

$$
\mathrm{COP}=\frac{\dot{Q}}{W}
$$

On the other hand, previous work (Sartor, Quoilin, and Dewallef 2014) based on Rolf, Henrik, and Judy (1999) is used to assess the cost of heat of a CHP plant connected to a DH network in function of the operating conditions. According to this model, the cost of heat is expressed as (Sartor, Quoilin, and Dewallef 2014)

$$
\mathrm{COH}=\frac{1}{\xi_{\mathrm{DHN}}}\left[\frac{C \cdot \psi+U_{\mathrm{fix}}}{P_{\mathrm{th}, \mathrm{chp}} \cdot \tau_{e}}+\frac{y_{\mathrm{f}}}{\bar{\eta}_{\mathrm{th}, \mathrm{chp}}}+u_{\mathrm{var}}-\left(y_{\mathrm{e}}+\tau_{\mathrm{cv}} y_{\mathrm{cv}}\right) \frac{\bar{\eta}_{\mathrm{el}, \mathrm{chp}}}{\bar{\eta}_{\mathrm{th}, \mathrm{chp}}}\right],
$$

where $C$ is the total investment cost, $\psi$ is the annuity factor which considers the present value of money and represents the annual repayment for the initial investment expressed in $€$ year ${ }^{-1}$. The annuity factor is assessed according to:

$$
\psi=\frac{d}{1-(1+d)^{-N}},
$$

where $d$ is the discounting rate per year and $N$ the number of years for which the installation is used (e.g. the life time of the plant). $P_{\text {th,chp }}$ is the installed thermal power of the CHP plant in MW and $\tau_{\mathrm{e}}$ is the equivalent utilisation time at rated power output. $\tau_{\mathrm{e}}$ embeds the availability factor of the plant (around 92\% for a biomass CHP plant [Rolf, Henrik, and Judy 1999]). $y_{\mathrm{f}}$ is the cost of fuel in $€ / \mathrm{MWh}, U_{\text {fix }}$ is the fixed cost of operation, maintenance and administration in $€ /$ year and $u_{\mathrm{var}}$ is the variable cost of operation, maintenance and repair in $€ / M W h . \bar{\eta}_{\text {th,chp }}$ is the average annual thermal efficiency taking into account the start/stop procedures (if any) and the part-load efficiency. $y_{\mathrm{e}}$ is the price of electricity in $€ / \mathrm{MWh}$ while $\tau_{\mathrm{cv}}$ and $y_{\mathrm{cv}}$ are respectively the number of green certificates per MWh of electricity produced. ${ }^{1}$ The term $\tau_{\mathrm{cv}} y_{\mathrm{cv}}$ is replaced by the premium on the electricity selling when feed-in tariffs are used instead. $\varepsilon_{\mathrm{DHN}}$ is defined as the ratio of the heat delivered to the consumer to the heat produced by the plant depending on the temperature level and the insulation of the network and the ambient conditions.

The determination of $C, U_{\mathrm{fix}}, u_{\mathrm{var}}, d$ and $N$ is not within the scope of the present contribution and reliable estimates can be found, for example, in Rolf, Henrik, and Judy (1999) and Energi Styrelsen LD (2012). Neither the influence of fuel cost nor the one of the supporting policies will be long discussed herein and representative value of the market in Belgium will be used, as it is relatively straightforward for the reader to include his proper data into the above model. The determination of $\tau_{\mathrm{e}}, \bar{\eta}_{e, \mathrm{chp}}$ and $\bar{\eta}_{\mathrm{th} \text {,chp }}$ is deduced from the thermodynamic model developed before by the authors in Sartor, Quoilin, and Dewallef (2014). $\varepsilon_{\mathrm{DHN}}$ is defined as the ratio of the heat delivered to the consumer to the heat produced by the plant.

Additionally, the thermodynamic models enable to assess the influence of the temperature level on the heat losses of the DH network. Using the above cost model, the influence of the temperature level is thus expressed in terms of the cost of heat per unit of heat delivered to the final customers.

Previous internal results (Sartor, Lemort, and Dewallef 2013) showed that a decrease of the feeder temperature of the $\mathrm{DH}$ network leads to a significant reduction in the heat losses and so leads to a reduction of the cost of heat. The balance between the savings due to lower heat losses and the electricity consumption of heat pumps could be performed to assess the economic viability of the solution. 
The current use of heat pump in DHN is widely studied for the fourth generation of DHN (Lund et al. 2010; Lund, Ilic, and Trygg 2016; Østergaard and Andersen 2016; Georges et al. 2017) to develop energy storage in the building, to reduce the temperature level of district heating network and the related heat losses and to improve the electricity network flexibility. However, the focus of the present contribution is intended for the use of heat pump only for the buildings which have high-temperature requirements to reduce the temperature level of the DH network while maintaining high-temperature requirements of these buildings. In this case, the related heat losses can be reduced.

\section{Simulation model}

\section{CHP plant}

A detailed zero-dimensional model of the CHP plant has been previously developed and validated in Sartor, Quoilin, and Dewallef (2014). The CHP plant is composed of a biomass furnace connected to a boiler. The boiler is composed of several heat exchangers, namely an economiser, an evaporator and a superheater. The steam generated by the boiler passes through two steam turbines for electricity production $\left(P_{\mathrm{el}, \mathrm{chp}}\right)$. After the high-pressure turbine, a fraction of the steam is extracted to feed a heat exchanger supplying the DH network heat demand $\left(P_{\text {th,chp }}\right)$, the remaining steam is expanded in a low-pressure turbine producing an additional amount of electricity. A schematic of the cycle is represented in Figure 1.

The incomplete combustion of biomass fuel is considered into the model. To achieve that chemical reaction kinetics coupled to a zero-dimensional model, steady-state thermodynamic model (Sartor et al. 2014) is used. It provides the assessment of the equilibrium composition in 15 relevant species in the flue gases: $\mathrm{H}_{2}, \mathrm{O}_{2}, \mathrm{H}_{2} \mathrm{O}, \mathrm{CO}, \mathrm{CO}_{2}, \mathrm{OH}, \mathrm{H}, \mathrm{N}_{2}, \mathrm{~N}, \mathrm{NO}, \mathrm{NO}, \mathrm{NO}_{2}, \mathrm{CH}_{4}, \mathrm{CO}_{2}, \mathrm{SO}_{3}$ and the adiabatic flame temperature.

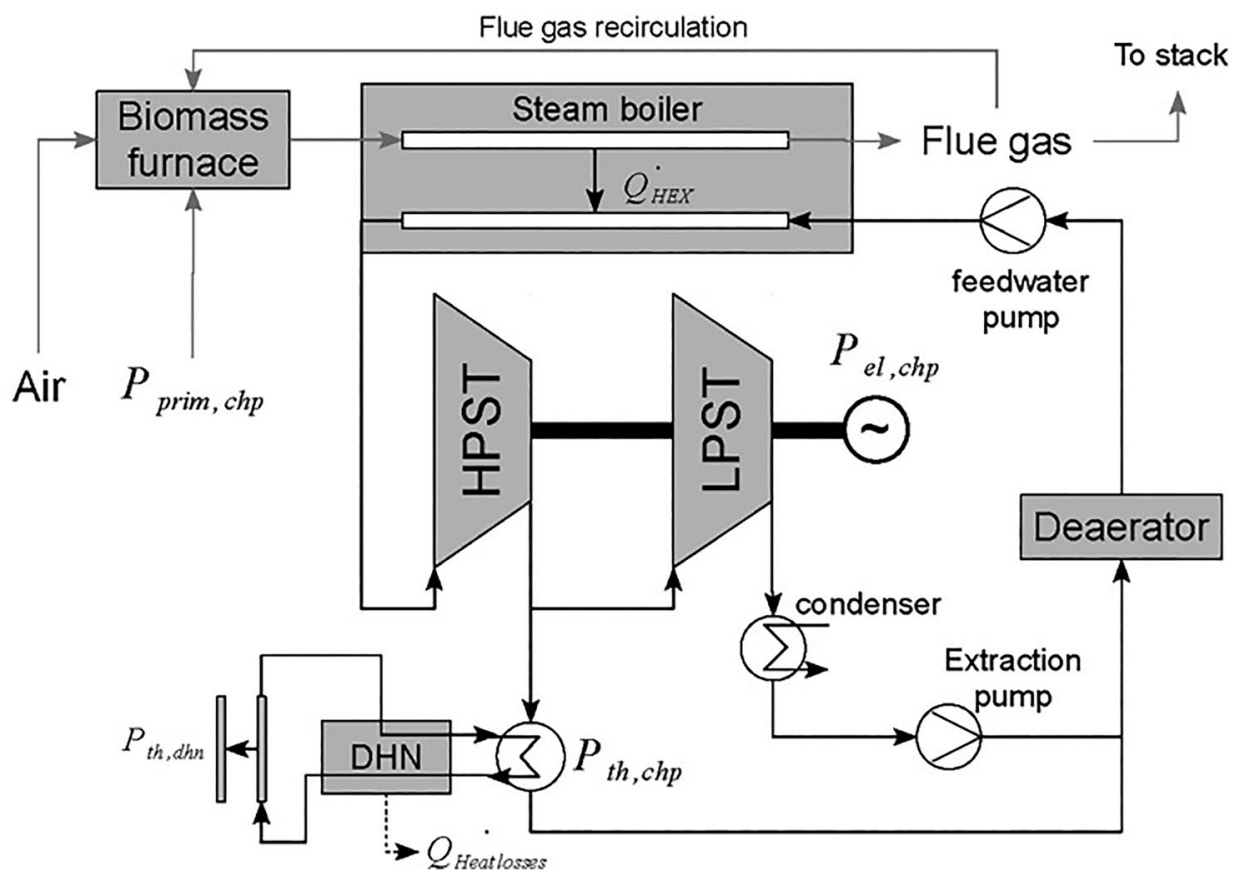

Figure 1. Schematic of CHP plant (Sartor, Quoilin, and Dewallef 2014). 
Once the composition and thermodynamic properties of the flue gas at the exhaust of the furnace are known, the heat transferred from the flue gases to produce the steam must be determined. The energy balance is performed with the calculation of the heat transfer between the water and the flue gases to assess mass flow rate and the temperature (see [Moran et al. 2010; Sartor, Quoilin, and Dewallef 2014] for further details).

\section{District heating network}

In DHN, the heat generated by the CHP plant is not fully delivered to consumers. Indeed, there are heat losses $\left(\dot{Q}_{\text {heatlosses }}\right)$ in the pipes, ensuring the heat transport as indicated in Figure 1. The assessment of these heat losses is critical while they could represent a significant energy lost (especially during the summer time).

A cross-section of the trench containing the supply and return pipes of the DH network is supplied in Figure 2.

To assess the heat losses, a model based on a steady-state two-dimensional heat transfer was previously developed. It considers conduction and convection and was validated on experimental data found in the literature and on measurements performed on the DHN of the University of Liège (Gary, Marlin, and David 1991; Paul 1999). The validation process concludes with a good agreement with experimental data (about 5\% of accuracy) for a wide range of DHN pipe configurations and heat losses $(50-140 \mathrm{~W} / \mathrm{m})$.

\section{Heat pump}

The steady-state model of the heat pump associates the sub-models of the four major components: the evaporator, the compressor, the condenser and the expansion valve (see Figure 3 ).

The compressor is modelled with a constant isentropic efficiency $\left(\varepsilon_{s}\right)$, which is defined as (the second equality being valid only if ambient losses are neglected)

$$
\varepsilon_{\mathrm{s}}=\frac{\dot{W}_{\mathrm{s}}}{\dot{W}}=\frac{h_{\mathrm{ex}, \mathrm{s}}-h_{\mathrm{su}}}{h_{\mathrm{ex}}-h_{\mathrm{su}}},
$$

where $\dot{W}$ is the power consumption of the compressor, $\dot{W}_{\mathrm{s}}$ is the power associated to an isentropic compression, $h_{\mathrm{su}}$ is the enthalpy at the supply of the compressor and $h_{\mathrm{ex}, \mathrm{s}}$ is the enthalpy at the exhaust of the compressor resulting from an isentropic compression between the evaporator pressure and the condenser pressure, and $h_{\mathrm{ex}}$ is the enthalpy at the exhaust of the compressor. In this study, an isentropic efficiency of $65 \%$ is considered (John and Elson 2004; Thumann and
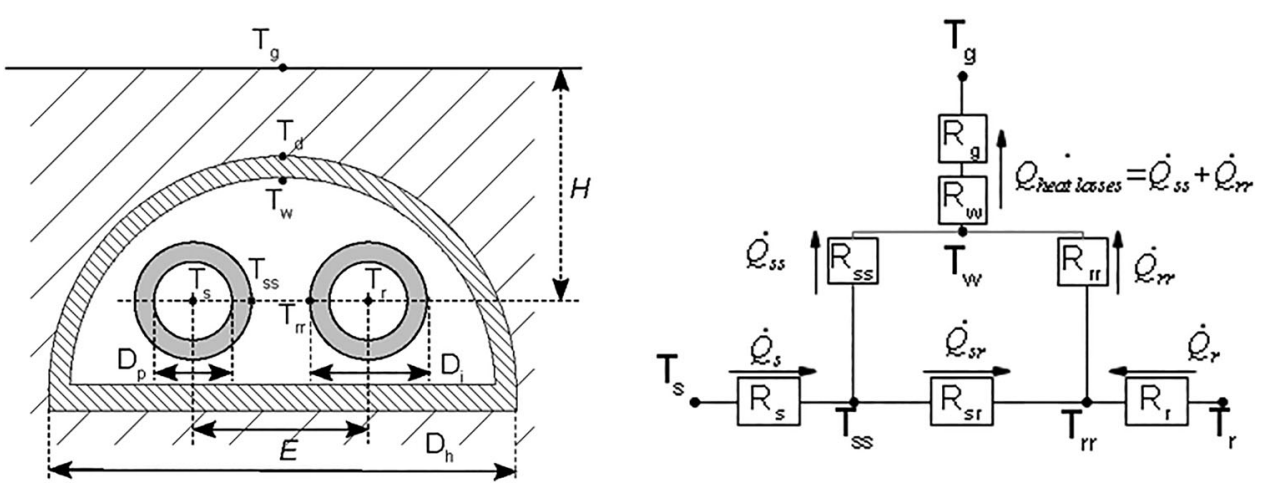

Figure 2. Trench used in the DH network at ULg (left: cross-section diagram; right: electrical equivalent) (Sartor, Quoilin, and Dewallef 2014). 


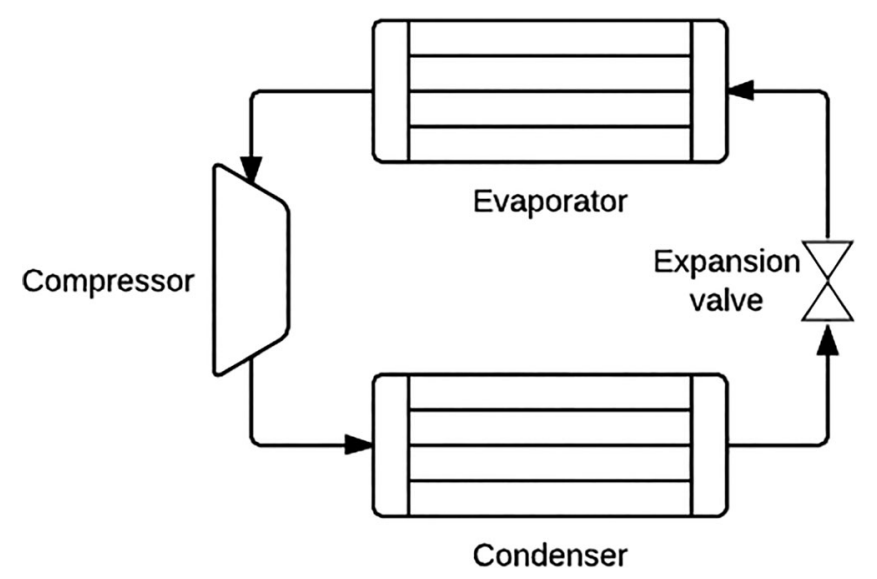

Figure 3. Heat pump diagram.

Mehta 2008; Cuevas et al. 2010). It is considered as constant at part-load (Winandy and Lebrun 2002; Cuevas et al. 2010) while in such heat pumps, variable-speed compressors can be used. The expansion process in the throttle valve of the cycle is considered to be isenthalpic. Heat exchangers (i.e. condenser and evaporator) are characterised by an efficiency of 65\% (VDI-Gesellschaft Verfahrenstechnik und Chemieingenieurwesen and Gesellschaft VDI 2010; Alfa 2015), leading to a minimum pinch point of $5 \mathrm{~K}$ in the current study. The heat transfer rate at the condenser $(\dot{Q})$ is fixed according to the steam or hot water needs. The sub-cooling at the exhaust of the condenser is taken equal to $6 \mathrm{~K}$ and the superheat at the exhaust of the evaporator is set to $4 \mathrm{~K}$ (American Society of Heating and Air Conditioning Engineers 2014). It should be noted that the secondary fluid in the condenser will be assumed to be hot-pressurised water in order to produce steam by expansion at a temperature of $120^{\circ} \mathrm{C}$.

Main parameters of the current contribution to assess the economic and environmental profitability of the use of high-temperature heat pump in DHN are the temperature of the cold source (herein the DHN temperature level) and the working fluid.

An engineering equation solver software (EES32) with built-in tabulated thermodynamic properties of several working fluids is used to perform the simulations.

The steam temperature at the exhaust of the heat pump will be considered equal to $120^{\circ} \mathrm{C}$ to keep the current hospital steam network without any extra investment costs. The water supply temperature level is assumed to vary between $80^{\circ} \mathrm{C}$ and $110^{\circ} \mathrm{C}\left(120^{\circ} \mathrm{C}\right.$ corresponding to the nominal case without using a heat pump). Two specific test cases are considered, which allow considering the coefficient of performance of the heat pump as constant even in part-load. The first case considers a heat pump coupled to a thermal storage, thus enabling the heat pump to work at full load all the time. To fulfil the requirements on steam imposed by its use in a hospital, and due to the steam demand profile, a reduced size of the heat storage is required. The reader is referred to Kulkarni, Kedare, and Bandyopadhyay (2008) for further insight on the design and costs of such high-temperature thermal storage. A pressurised water tank is used to store water at a temperature over $100^{\circ} \mathrm{C}$ and when the heat pump cannot provide the hospital steam demand, a part of the water stored is expanded to produce steam. The second one is a heat pump without heat storage but composed of several compressors (variable and fixed-speed) working in parallel. For the variable-speed compressor, a constant efficiency is assumed at part-load (Qureshi and Tassou 1996; Benamer and Clodic 1999). The other compressors work either at full load and thus at their nominal efficiency or can be switched off if required by the load. Performance degradation due to on/off cycles of the fixed-speed compressors is not considered in this case. Therefore the efficiency of the global compressor group can be considered as constant (Rivière 2004). An example is available in Figure 4 for a configuration with two compressors. 


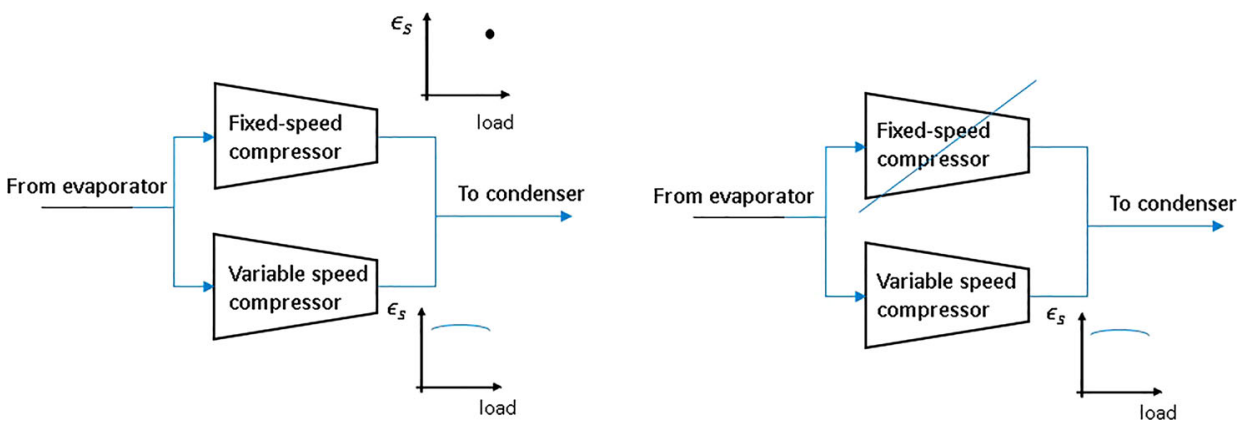

Figure 4. Example of configurations with two compressors for a load ranging $50 \%$ and $100 \%$ (left) and between $0 \%$ and $50 \%$ (right).

While heat exchangers are designed at their maximum load, their efficiency increases at part-load due to the heat transfer area available for a lower heat transfer rate (other parameters being considered unchanged). This, combined to a reduced refrigerant mass flow at part-load (and hence reduced power used by the compressor), leads to a higher coefficient of performance of the system. However, in this work, a conservative assumption of constant coefficient of performance is chosen.

To summarise the methodology of the model, the inputs (in bold), the parameters ${ }^{2}$ (in the upper boxes), the outputs (in bold and italic), and the iteration variables (the remaining ones in italic) of the model are schematised in Figure 5. $T$ stands for temperature, $P$ for pressure, $h$ for enthalpy, $\dot{Q}$ for heat rate, $\dot{M}$ for mass flow rate and $\dot{W}$ for the electric consumption. The subscript cs stands for cooling source, $\mathrm{cp}$ for compressor, ev for evaporator, $\mathrm{cd}$ for condenser, su for supply, ex for exhaust, $r$ for refrigerant.

\section{Application}

\section{Description}

The heating plant and the DHN of the University of Liège are used as an application test case. The $\mathrm{DHN}$ has a length of $10 \mathrm{~km}$ and it fed pressurised hot water at a mean temperature of $120^{\circ} \mathrm{C}$. About

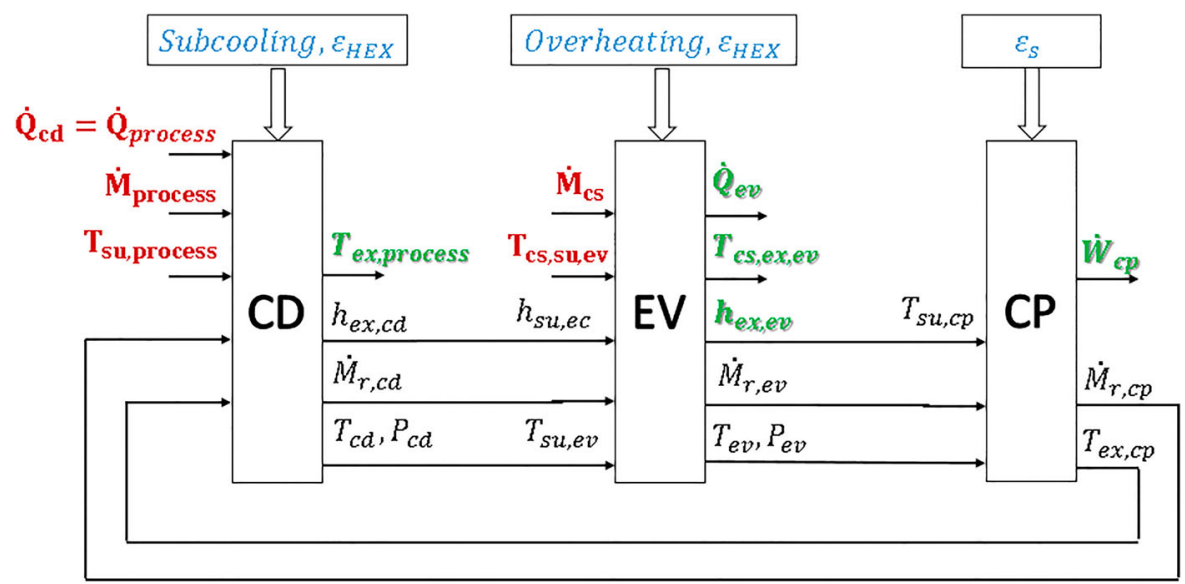

Figure 5. Model block diagram. 
70 buildings are connected to the DHN and represent a total heated area of $470,000 \mathrm{~m}^{2}$. The heat demand profile of the buildings is different due to their affectation: classrooms, research centres, administrative offices and a hospital. This last building represents about $25 \%$ of the total heated area and it is the only building which requires steam. This steam is used in the kitchen (washing machines) and in its humidity control system. The effective peak power of the DHN is $56 \mathrm{MW}$ for a total heat demand of around $61 \mathrm{GWh}$.

Heat is supplied to all the buildings from 4:00 to 20:00 apart from the hospital which requires heat 24 hours a day. Considering the daily heat demand profile, there is a peak at 7:00 to heat buildings in the morning and a second peak at 16:00. On the other hand, the annual hospital steam needs is $366 \mathrm{MWh}$. The steam demand profile of the hospital is represented in Figure 6 (right). It is quite constant for 11 hours at full capacity and at partial load (33\%) for 9 hours. This behaviour supports the previous hypothesis: the coefficient of the heat pump can be considered as constant if several compressors are used in the cycle.

The DH network is operating since the 60's. Previously, the heat was generated by natural gas boilers. In Belgium $\mathrm{CO}_{2}$ quotas were introduced in 2012. Therefore, to cope with the quotas, the University of Liège decided to invest in biomass CHP plant, whose purpose is to feed the baseline heat demand of the campus and its operation started in 2012. It is made of a moving grid biomass boiler with nominal primary power of $12 \mathrm{MW}$, providing the steam to a back-pressure turbine and an extraction condensing turbine with nominal power of $2.4 \mathrm{MW}$. The extracted steam is condensed in a heat exchanger feeding the DH network with a nominal thermal power of $7 \mathrm{MW}$. To ensure the heat demand of the DHN, the remaining thermal power is provided by two natural gas boilers. The primary energy of the CHP plant is wood pellets whose wet basis mass composition is $46.38 \%$ of $\mathrm{C}, 5.64 \%$ of $\mathrm{H}, 40.01 \%$ of $\mathrm{O}, 0.08 \%$ of $\mathrm{N}, 0.28 \%$ of ashes, $7.6 \%$ of water and less than $0.01 \%$ of S. A schematic of the plant configuration is supplied in Figure 7 (Sartor, Quoilin, and Dewallef 2014).

The biomass feeding system is a moving grid in a combustion chamber without staged-air combustion supply. Exhaust fumes must be recirculated after a second air injection to limit the temperature. Indeed, the combustion with limited air excess of wood pellets leads to too high a flame temperature. Moreover additional air injection is performed to maintain the moving grid in working temperature ranges. The flue gas at the exhaust of the furnace passes successively through an evaporator (platen), screen tubes, two superheaters, one evaporator and four economisers. Exhaust gases are filtered before being directed to the stack. The steam cycle is representative of a traditional cycle with extraction turbines.
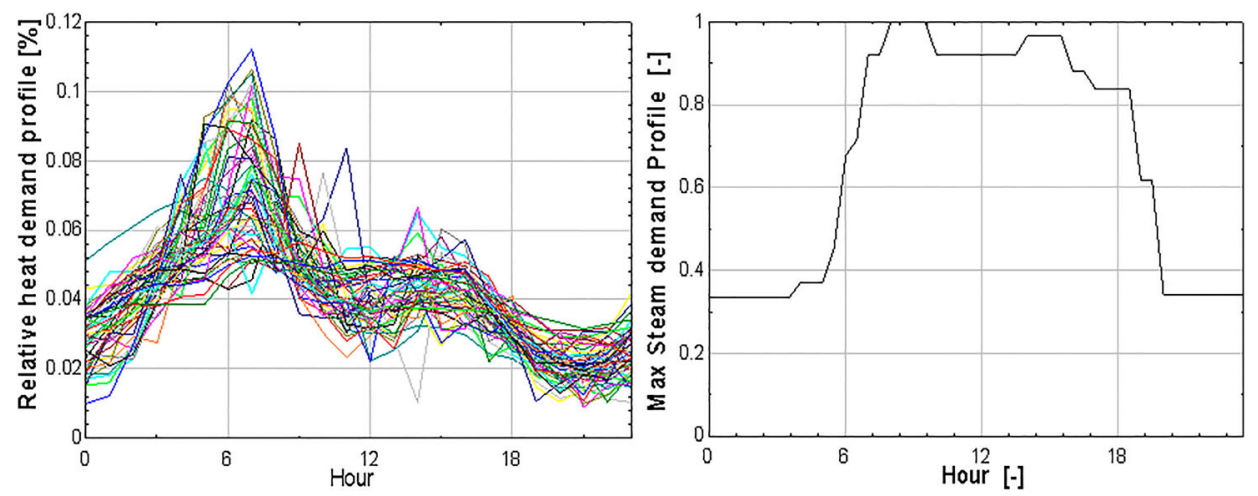

Figure 6. Relative heat demand profile of the DH network for several days (left) and steam demand profile of the hospital in function of the hour of the day (right). 


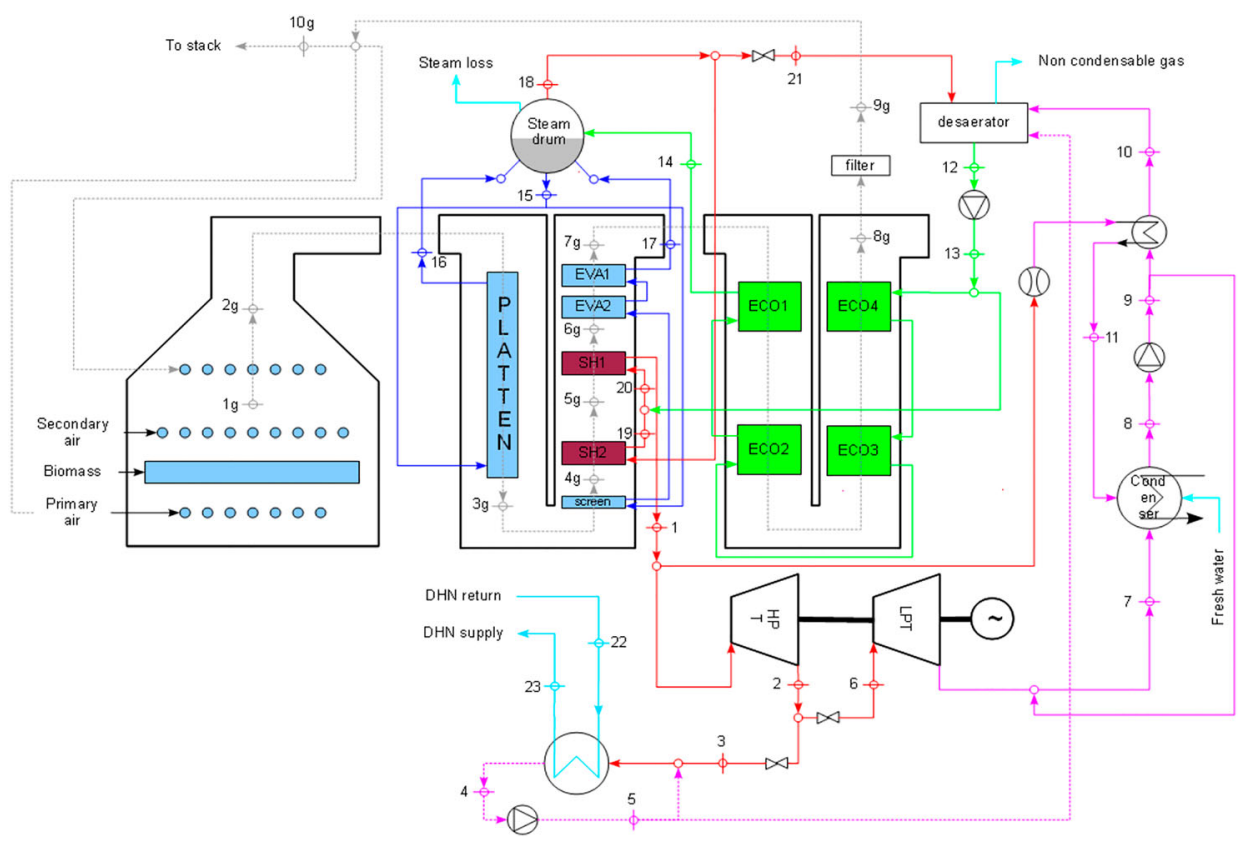

Figure 7. Detailed schematic of CHP plant.

The district heating network is divided into 23 sections having the same geometric characteristic of pipe diameters ranging from 50 to $350 \mathrm{~mm}$. The insulation is mineral wool with an identified thermal conductivity of $0.047 \mathrm{~W} / \mathrm{m} / \mathrm{K}$.

\section{Simulation results}

The integrated model of CHP plant and DH network calculates the heat losses and the cost of heat as a function of the temperature level in the DH network pipes (Table 1). Currently the temperature is approximately around $120^{\circ} \mathrm{C}$. The minimum temperature level investigated is $80^{\circ} \mathrm{C}$ as below this temperature level the sub-stations of the $\mathrm{DH}$ network are unable to supply the heat transfer to ensure users' comfort conditions inside the buildings. Of course, the lower the temperature level of the feeders, the lower the heat losses (Figure 8). These results lead to reduced heat losses and so reduced annual heat demand, which leads to an annual saving up to $205 \mathrm{k} €$ per year. For further details concerning the determination of the cost of heat, the reader can be referred to Danish Energy Agency (2012b) and Sartor, Quoilin, and Dewallef 2014).

Table 1. Simulation results for several temperature levels of the $\mathrm{DH}$ network.

\begin{tabular}{lccc}
\hline DH network temp. level $\left({ }^{\circ} \mathrm{C}\right)$ & Cost of heat $(€ / \mathrm{MWh})$ & Annual heat demand (MWh/year) & Annual cost (k€/year) \\
\hline 80 & 60.58 & 58,891 & 3567.6 \\
85 & 60.77 & 59,159 & 3595.1 \\
90 & 60.97 & 59,424 & 3623.1 \\
95 & 61.17 & 59,681 & 3650.7 \\
100 & 61.37 & 59,938 & 3678.4 \\
105 & 61.54 & 60,161 & 3702.3 \\
110 & 61.69 & 60,355 & 3723.3 \\
Nominal case: $\sim 120$ & 62.04 & 60,804 & 3772.3 \\
\hline
\end{tabular}




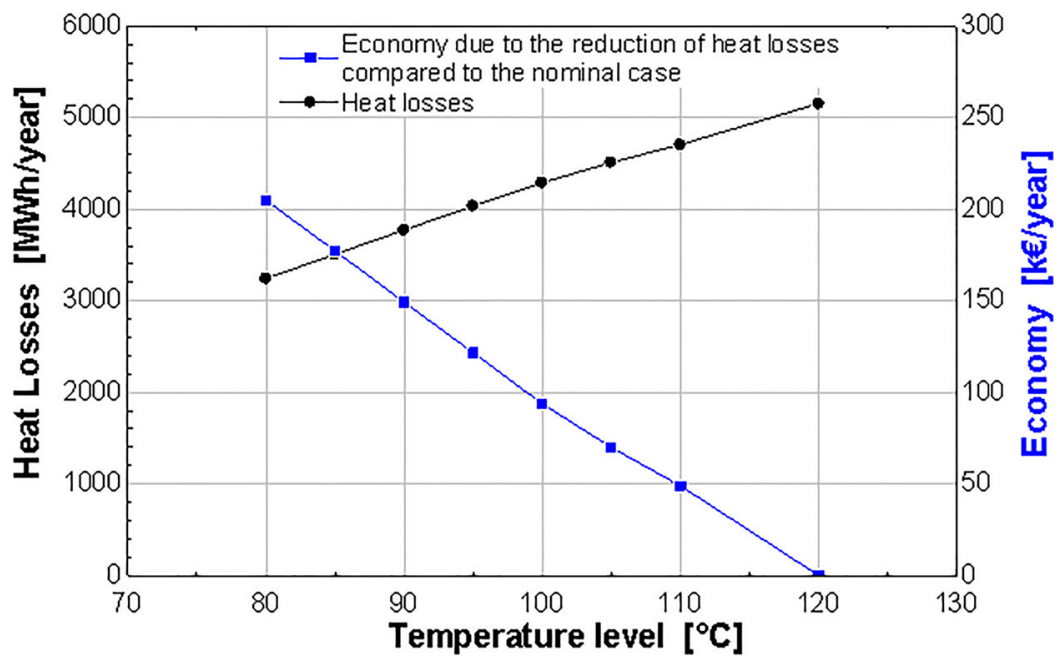

Figure 8. Heat losses and economy in function of temperature level of the $\mathrm{DH}$ network.

Concerning the heat pump study, five refrigerants are investigated, namely R245FA, SES36, ammonia, n-pentane and ethanol. This choice is justified by their common use in the industry or because of their interesting properties at these temperatures even if some of them are still in development (Stene 2008; Maxime Dupont ES 2009; Peureux, Sapora, and Bobelin 2012; Wolf et al. 2012). On the other hand, the working fluid of Engines VH (2016) is not available. To meet the steam demand, two cases are investigated. The first one where heat storage is used corresponds to constant thermal power at all time (the peak load is provided by the heat storage). The second case is where the heat pump must follow the steam demand exhibited in the graph in Figure 6 without heat storage. In this case, the condenser thermal peak power increases by $35 \%$ to ensure the peak load can be provided.

For both cases, the resulting coefficients of performance at full load are shown in Figure 9 for the different working fluids investigated in function of the temperature level of the DH network. This temperature corresponds to the evaporator temperature level: for the sake of simplicity, the coefficient of performance is supposed not to vary as a function of the heat transfer at the condenser; so the results are valid for both cases. Depending on the configuration, the resulting coefficient of performance varies between 2 up to 13. It decreases when the temperature level decreases, that is, the losses of the DH network also decrease. The best working fluid is the ethanol, which gives a coefficient of performance from about 5-13. It is interesting to note that this preliminary study neither consider the explosion risk linked to the use of ethanol in the cycle nor the corresponding higher investments (especially for ATEX compressors).

In Figure 10, the thermodynamic cycle is represented for the ethanol as working fluid for a $\mathrm{DH}$ network of $100^{\circ} \mathrm{C}$. Due to lower temperature difference between condenser and evaporator, the pumping work is not so high leading to a high coefficient of performance, here about 8 .

\section{Balance of the cost and environmental impacts}

The lifetime of the heat pump and the optional heat storage are considered equal to 20 years with a discount rate of $5 \%$. In terms of investments, common heat pumps costs vary between 500 and $1300 €$ per installed kW thermal (Danish Energy Agency 2012a, 2012b; Energiesysteme T). Despite the variability of the costs of the working fluid and the compressors, this preliminary study is focused on a rough estimation of the profitability related to the proposed solution. Therefore, a conservative value of $1300 €$ per installed kW thermal is considered herein (Danish Energy Agency 2012a). This 


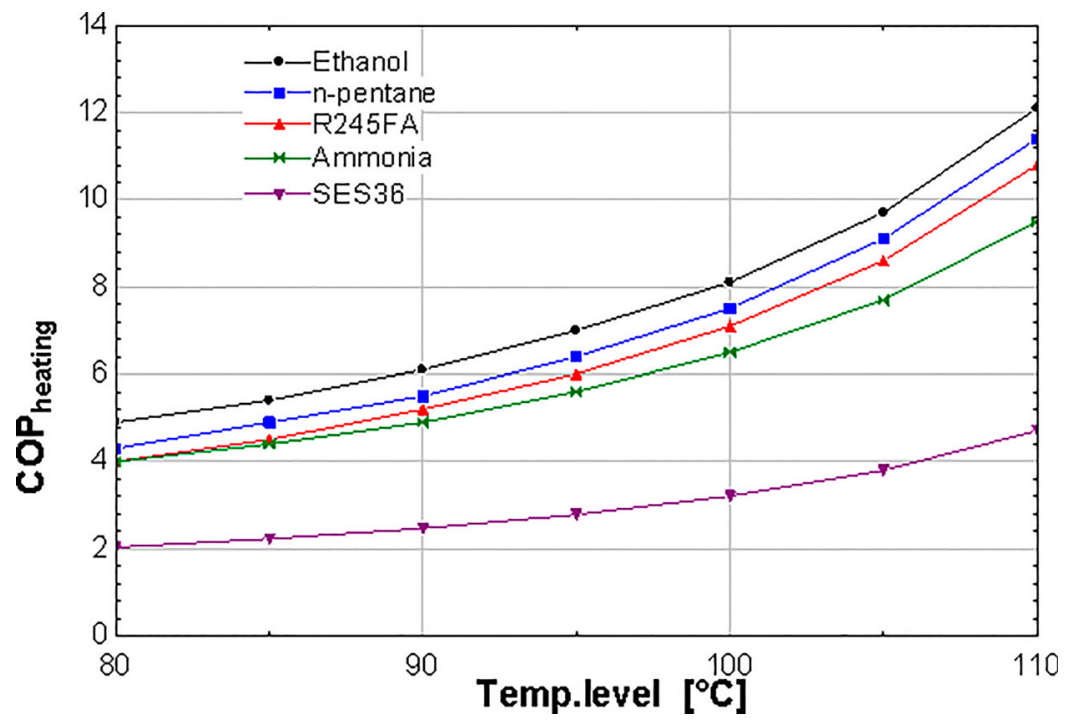

Figure 9. Coefficient of performance of a heat pump in function of the temperature level of the DH network for several working fluids.

conservative value is reinforced by the fact that the investment costs of a commercial high-temperature heat pump (Engines VH 2016) are $900 €$ per installed kW thermal. For the same reason, only the best (ethanol) and the worst (SES36) working fluid are referred in this section. The operation and maintenance costs are estimated at $7.3 €$ per kW thermal (Danish Energy Agency 2012b). The electricity used by the University of Liège is accounted at the rate of $112.7 € / \mathrm{MWhe}$, which corresponds to an intermediate price between the industrial and household consumers (Eurostat 2017). Heat storage costs are assumed $1000 € / \mathrm{m}^{3}$ (Danish Energy Agency 2012b). Assuming an energy of $40 \mathrm{kWh}$ per $\mathrm{m}^{3}$ of heat storage (Danish Energy Agency 2012b), a volume of $10 \mathrm{~m}^{3}$ will be considered to store enough heat to satisfy the daily steam demand of the hospital.

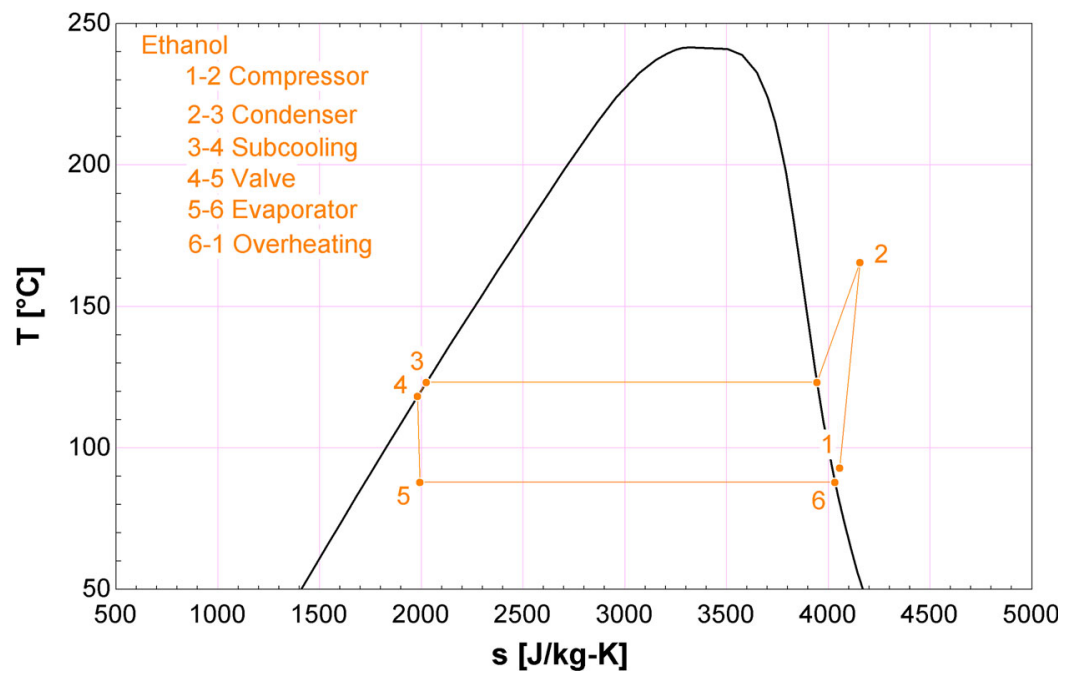

Figure 10. Thermodynamic cycle diagram with ethanol as working fluid for a $\mathrm{DH}$ network temperature of $100^{\circ} \mathrm{C}$. 


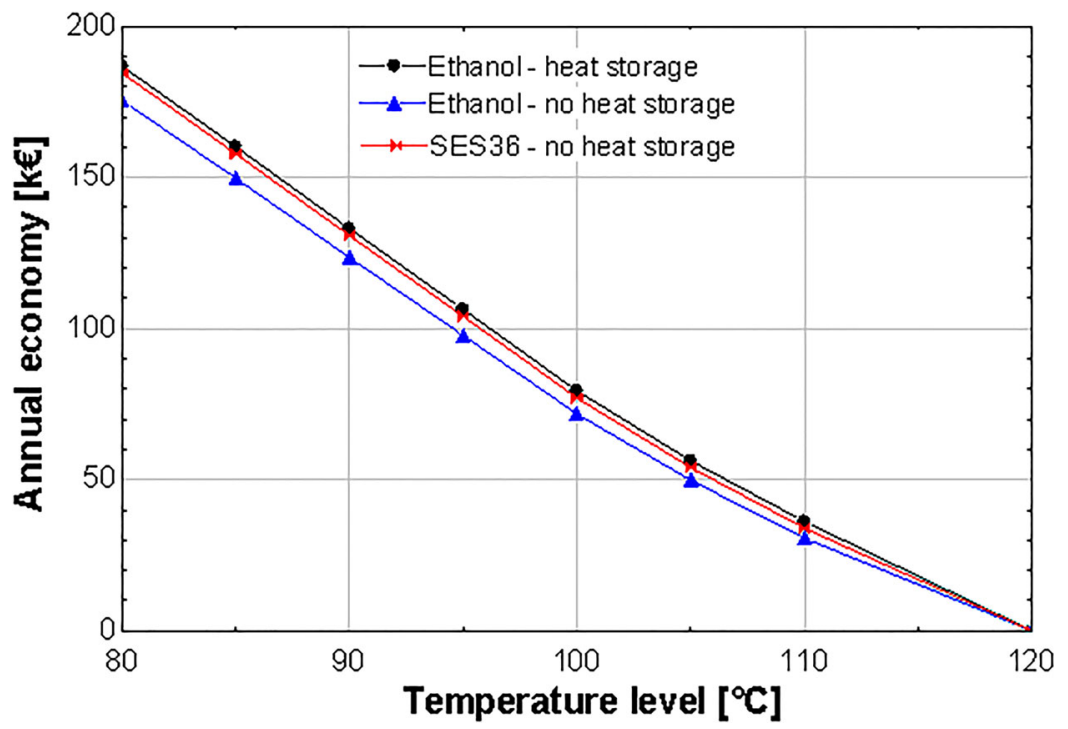

Figure 11. Annual economy in $k €$ of the use of high-temperature heat pump in function of the temperature level and the use or no heat storage with ethanol as working fluid.

Table 2. $\mathrm{CO}_{2}$ emissions for the difference considered cases.

\begin{tabular}{lccr}
\hline Conditions & Nominal case $\left(t \mathrm{CO}_{2} /\right.$ year $)$ & \multicolumn{2}{c}{ Improved case $\left(t \mathrm{CO}_{2} /\right.$ year $)$} \\
\hline Working fluid & $/$ & $\mathrm{SES} 36$ & Temperature level of $80^{\circ} \mathrm{C}$ \\
CHP consumption & 2033 & 1998 & 1998 \\
Back-up boilers & 8299 & 7859 & 7859 \\
Heat pump electricity & 0 & 83 & 34 \\
Total & 10332 & 9940 & 9890 \\
\hline
\end{tabular}

Figure 11 does not show an optimum: the lower the feeder temperature, the more important is the annual saving. Therefore, from an economic point of view, it is better to use the heat pump with the lowest evaporator temperature possible. The use of the heat storage leads to a slightly higher saving due to the lower investment compared to the one related to a condenser heat pump with a higher peak load.

Assuming natural gas releases $251 \mathrm{~g}$ of $\mathrm{CO}_{2}$ per thermal $\mathrm{kWh}$ and $456 \mathrm{~g}$ of $\mathrm{CO}_{2}$ per electrical $\mathrm{kWh}$ (CWAPE) and biomass fuel only releases $30 \mathrm{~g}$ of $\mathrm{CO}_{2}$ per $\mathrm{kWh}$, Table 2 shows the $\mathrm{CO}_{2}$ emissions due to the biomass consumption for the heat and electricity production of the CHP plant, for the natural gas back-up boilers consumption and for the electricity consumption of the heat pump (if any). Heat loses mainly appear when CHP works at full load (in winter and intermediate seasons when heat demand is higher) and, consequently, when the natural gas back-up boilers are also often used. So the main reduction of $\mathrm{CO}_{2}$ emissions occurs for the natural gas boilers due to their lower use. For the environmental influence, the use of a heat pump enables a significant reduction in $\mathrm{CO}_{2}$ emissions (about $4 \%$ ).

\section{Conclusions}

The opportunity to decrease the temperature level of a DH network was investigated to reduce the inherent heat losses of the DH network and therefore to reduce the cost of heating. If some consumers of the $\mathrm{DH}$ network require steam or high-temperature heat, the integration of high- 
temperature heat pump is considered in order to locally increase the temperature level. Combined with previous research, this contribution presents a way to assess the profitability of the project by considering its energetic, economic and environmental aspects. A thermodynamic model of the heat pump is used to determine the achievable coefficient of performance from the available temperature levels of cold sources, that is, $\mathrm{DH}$ temperature level, and working fluids. This model is integrated into the whole model of the CHP plant connected to a DH network previously developed. The balance between heat loss reduction and investment and operation costs of the heat pump is assessed. This way, the proposed approach can be considered as a support decision tool for the improvements of the $\mathrm{DH}$ network.

As expected in the case-study, the reduction of the temperature level from about $120^{\circ} \mathrm{C}$ to $80^{\circ} \mathrm{C}$ leads to a reduction of the heat losses of up to 1900 MWh per year. This represents $-37 \%$ compared to the actual case. The coefficient of performance of the proposed heat pump ranges from 2 to 5 depending on the nature of the working fluid. The expected profitability is significant and reaches up to $186 \mathrm{k} €$ per year. In addition, significant $\mathrm{CO}_{2}$ emissions reductions are obtained for all considered conditions and ethanol seems to be the best working fluid. A more detailed study is needed to confirm the conclusions of the present contribution that could take into account the compressor technology to use, depending on the selected working fluid. This study would derive an accurate estimate of the coefficient of performance and investment costs for such technology.

To conclude, the use of heat pumps at some locations of the DH network adds more flexibility to the plant and to the DH network operation. It increases the efficiency of the plant and reduces the $\mathrm{DH}$ network heat losses. Moreover, the integration of such heat pumps with heat storage can be investigated to check the profitability of retrofitted systems and to estimate the resulting increase in terms of the number of equivalent running hours at a full rate of the CHP plant and so its energetic efficiency.

\section{Notes}

1. For the Walloon region of Belgium, one green certificate is granted for every $456 \mathrm{~kg}$ of $\mathrm{CO}_{2}$ saving. A maximum of two green certificates is allowed per MWh of electricity produced.

2. Defined previously in this section.

\section{Disclosure statement}

No potential conflict of interest was reported by the authors.

\section{ORCID}

Kevin Sartor (D) http://orcid.org/0000-0001-5494-1824

\section{References}

Alfa, L. 2015. Internal Report. www.alfalaval.com.

American Society of Heating and Air Conditioning Engineers. 2014. R, American Society of Heating R and A-CE. 2014 Ashrae Handbook. http://app.knovel.com/hotlink/toc/id:kpASHRAEED/2014-ashrae-handbook.

Benamer, A., and D. Clodic. 1999. "Comparison of Energy Efficiency Between Variable and Fixed Speed Scroll Compressors in Refrigerating Systems." Technological Innovations in Refrigeration, in Air Conditioning and in the Food Industry into Third Millennium, June 18-19, 1-8.

Besbes, K. 2015. High Temperature Industrial Heat Pumps Recovering Heat on Medium Temperature Saturated Air or Vapor. Paris: Mines Paristech.

Chamoun, M., R. Rullier, P. Haberschill, and J.-L. Peureux. 2012. "Experimental Investigation of a New High Temperature Heat Pump Using Water as Refrigerant for Industrial Heat Recovery." Paper presented at the International Refrigeration and Air Conditioning Conference, Purdue, July 16-19.

Cuevas, C., J. Lebrun, V. Lemort, and E. Winandy. 2010. "Characterization of a Scroll Compressor under Extended Operating Conditions.” Applied Thermal Engineering 30 (6-7): 605-615. doi:10.1016/j.applthermaleng.2009.11.005. 
CWAPE. CWaPE [Internet]. www.cwape.be.

Danish Energy Agency. 2012a. Technology Data for Energy Plants - Generation of Electricity and District Heating, Energy Storage and Energy Carrier Generation and Conversion. Kongens Lyngby: Danish Energy Agency.

Danish Energy Agency. 2012b. Technology Data for Energy Plants - Individual Heating Plants and Energy Transport. Kongens Lyngby: Danish Energy Agency.

Dobos, L., and J. Abonyi. 2011. "Controller Tuning of District Heating Networks Using Experiment Design Techniques.” Energy 36: 4633-4639.

Energiesysteme T. Steam Generation from Waste Heat. energiesysteme T, editor.

Energi Styrelsen LD. 2012. Technology Data for Energy Plants: Generation of Electricity and District Heating. Kongens Lyngby: Energy Storage Energy Carr Gener Convers.

Engines VH. 2016. New Industrial Heat Pump Produces Heat in the Very High Temperature Range. Engines VH. http://www.vikingheatengines.com/news/new-industrial-heat-pump-produces-heat-in-the-very-hightemperature-range.

Eurostat. 2017. Detailed Statistics on the EU and Candidate Countries, and Various Statistical Publications for Sale. Eurostat. http://ec.europa.eu/eurostat.

Gary, E. P., J. K. Marlin, and L. C. L. Fm David. 1991. Field Measurements of Heat Losses from Three Types of Heat Distribution Systems. Washington, DC: U.S. Army Corps of Engineers.

Georges, E., B. Cornélusse, D. Ernst, V. Lemort, and S. Mathieu. 2017. "Residential Heat Pump as Flexible Load for Direct Control Service with Parametrized Duration and Rebound Effect.” Applied Energy 187: 140-153.

John, P., and B. R. B. Elson. 2004. A Hermetic Scroll Compressor for Application to High Heat-of-Compression Gases. Austin, TX: Emerson Process Management and Copeland Scroll.

Kulkarni, G. N., S. B. Kedare, and S. Bandyopadhyay. 2008. "Design of Solar Thermal Systems Utilizing Pressurized Hot Water Storage for Industrial Applications.” Solar Energy 82 (8): 686-699. doi:10.1016/j.solener.2008.02.011.

Lund, R., D. D. Ilic, and L. Trygg. 2016. "Socioeconomic Potential for Introducing Large-Scale Heat Pumps in District Heating in Denmark." Journal of Cleaner Production 139: 219-229.

Lund, H., B. Moller, B. V. Mathiesen, and A. Dyrelund. 2010. "The Role of District Heating in Future Renewable Energy Systems.” Energy 35 (3): 1381-1390.

Maxime Dupont ES. 2009. "The Heat Recovery Potential in the French Industry: Which Opportunities for Heat Pump Systems?” ECEEE 2009 Summer Study. ECEEE. http://www.eceee.org/library/conference_proceedings/eceee Summer_Studies/2009/Panel_5/5.129.

Moran, M. J., H. N. Shapiro, D. D. Boettner, and M. B. Bailey. 2010. Fundamentals of Engineering Thermodynamics. Wiley. https://books.google.ca/books?id=oyt8iW6B4aUC.

Østergaard, P. A., and A. N. Andersen. 2016. "Booster Heat Pumps and Central Heat Pumps in District Heating." Applied Energy 184: 1374-1388. doi:10.1016/j.apenergy.2016.02.144.

Paul, W. R. 1999. “Two-Dimensional Analysis of Natural Convection and Radiation in Utilidors.” US Army Corps of Engineers.

Peureux, J.-L., E. Sapora, and D. Bobelin. 2012. Very High-Temperature Heat Pumps Applied to Energy Efficiency in Industry. Frankfurt am Main: Achema.

Quoilin, S., S. Declaye, A. Legros, L. Guillaume, and L. Vincent. 2012. "Working Fluid Selection and Operating Maps for Organic Rankine Cycle Expansion Machines." Paper presented at the proceedings of the 21st International Compressor Conference, Purdue, July 16-19.

Qureshi, T. Q., and S. A. Tassou. 1996. "Variable-Speed Capacity Control in Refrigeration Systems.” Applied Thermal Engineering 16 (2): 103-113. doi:10.1016/1359-4311(95)00051-E.

Rezaie, B., and M. A. Rosen. 2012. "District Heating and Cooling: Review of Technology and Potential Enhancements." Applied Energy 93: 2-10. doi:10.1016/j.apenergy.2011.04.020.

Rivière, P. 2004. Performances saisonnières des groupes de production d'eau glacée. Paris: Ecole des Mines de Paris.

Rolf, B., N. Henrik, and W. Judy. 1999. Combined - Cycle Gas \& Steam Turbine Power Plants. Tulsa, OK: PennWell Books.

Sartor, K., V. Lemort, and P. Dewallef. 2013. "Improved District Heating Network Operation by the Integration of High Temperature Heat Pumps.” Paper presented at the 8th conference on Sustainable Development of Energy, Water and Environment Systems, Dubrovnik, Croatia, September 22-27, 1-10.

Sartor, K., S. Quoilin, and P. Dewallef. 2014. "Simulation and Optimization of a CHP Biomass Plant and District Heating Network.” Applied Energy 130: 474-483. doi:10.1016/j.apenergy.2014.01.097.

Sartor, K., Y. Restivo, P. Ngendakumana, and P. Dewallef. 2014. "Prediction of SOx and NOx Emissions from a Medium Size Biomass Boiler.” Biomass and Bioenergy 65: 91-100.

Stene, J. 2008. "Design and Application of Ammonia Heat Pump Systems for Heating and Cooling of Non-residential Buildings." 8th IIR Gustav Lorentzen Conference on Natural Working Fluids, IIR, Copenhagen.

Thumann, A., and D. P. Mehta. 2008. Handbook of Energy Engineering. Lilburn, GA: Fairmont Press. http://books. google.be/books?id=HLcEJJ0odeoC.

Varun, I. K. Bhat, and P. Ravi. 2009. "LCA of Renewable Energy for Electricity Generation Systems - A Review." Renewable and Sustainable Energy Reviews 13: 1067-1073. doi:10.1016/j.rser.2008.08.004. 
VDI-Gesellschaft Verfahrenstechnik und Chemieingenieurwesen and Gesellschaft VDI. 2010. VDI heat atlas. Chemieingenieurwesen VD-GV und, editor. Springer.

Wang, K., F. Cao, S. Wang, and Z. Xing. 2010. "Investigation of the Performance of a High-Temperature Heat Pump Using Parallel Cycles with Serial Heating on the Water Side." International Journal of Refrigeration 33 (6): 11421151. doi:10.1016/j.ijrefrig.2010.04.016.

Winandy, E. L., and J. Lebrun. 2002. "Scroll Compressors Using Gas and Liquid Injection: Experimental Analysis and Modelling." International Journal of Refrigeration 25 (8): 1143-1156. doi:10.1016/S0140-7007(02)00003-8.

Wolf, S., J. Lambauer, U. Fahl, M. Blesl, and A. Voß. 2012. "Industrial Heat Pumps in Germany - Potentials, Technological Development and Application Examples." ECEEE 2012 - Summer Study on Energy Efficiency in Industry, Achema, Germany.

Zhang, S., H. Wang, and T. Guo. 2010. "Experimental Investigation of Moderately High Temperature Water Source Heat Pump with Non-Azeotropic Refrigerant Mixtures.” Applied Energy 87 (5): 1554-1561. doi:10.1016/j.apenergy. 2009.11.001. 